\title{
The Accurate Marketing System Design Based on Data Mining Technology: A New Approach
}

\author{
ZENG Yuling ${ }^{1, a}$ \\ ${ }^{1}$ Wuhan Polytechnic, Wuhan 430074, China \\ azengyuling@126.com
}

Keywords: Data Mining; Big Data Classification and Recognition; Precision Marketing System.

\begin{abstract}
With the rapid development of mobile Internet, operators are faced with the increasingly fierce competition. Big data includes Internet, medical equipment, video monitoring, mobile devices, smart devices, non-traditional IT equipment such as channel mass structured or unstructured data, and every moment of the day in continuously penetrate into all aspects of the daily management and operation of modern enterprises. We design and implement the precision marketing system under the big data environment in the paper and the result proves the effectiveness and robustness of our method compared with other systems. The prospect is set in the final part.
\end{abstract}

\section{Introduction}

With the rapid development of mobile Internet, operators are faced with the increasingly fierce competition, traffic management is imperative, based on user behavior analysis precision is an important marketing tool. But in the era of big data, along with the rapid growth of the mobile Internet business and the number of users, the traditional architecture is difficult to adapt to the requirement of huge amounts of data mining. In the past few years, information technology in various fields such as society, economy and life continues to infiltrate and innovating. In mobile computing, Internet of things, the support of a number of emerging technologies such as cloud computing, social media, collaborative creation, the new applications such as virtual service pattern continued to expand the scope of human creation and use of information and forms [1-2]. In the era of big data, data has been penetrated into every industry today and the business functional areas, become an important production factor. For huge amounts of data mining and utilization, herald a new wave of productivity growth and the influence of the consumer surplus. Review of nearly two years of the great data exploration course, some basic operators on the one hand, conform to the trend, firmly grasp the opportunity of rapid development technology of data, on the other hand should be potential, fully release early IT centralization, the integration of the dividends, firmly promote the data set. Successively experienced data set collected data accumulation, try a large Hadoop platforms, traditional database and Hadoop mix structure of big data platform to create, and currently the open big data service platform into four stages [3-4]. Accurate marketing and support system, relying on large data precision positioning support end-to-end multidimensional sustaining system, build on big data platform, customer oriented, service oriented, geared to the needs of management, deepen the ability of data analysis, data mining, insight into the customer, the enterprise perspective, is the large data into actual productivity of one of the important cloud application [5].

Big data includes Internet, medical equipment, video monitoring, mobile devices, smart devices, non-traditional IT equipment such as channel mass structured or unstructured data, and every moment of the day in continuously penetrate into all aspects of the daily management and operation of modern enterprises. Companies from trading data generated continuously for trillions of bytes of information about consumers, suppliers and operational management; One million network sensors implanted into cell phones, smart meters, automobile and machinery equipment to induction, such as creating and exchanging data; Hundreds of millions of Internet users in the social media group of real-time communication and sharing are also big data play an important role in the process of exponential growth; Internet users upload every second high resolution video images, text will 
generate more than single page 2000 times the byte data storage content. Therefore, to follow the trend of big data environment, we propose a novel methodology of precision marketing system based on data mining and analysis technique in this paper. The detailed discussions are shown in the next sections.

\section{System Design and Analysis}

Core Techniques of Data Mining. Semantic engine is a way to extract useful information from unstructured data of a tool. Relative to the structured data, not convenient to use the database of two-dimensional logical table to represent the data that is called unstructured data, including all the office document formats, text, images, XML, HTML, all kinds of statements, image and audio/video information, etc. Data mining algorithm is a process of constantly verification matching, data analysis and business personnel need to continue to communication and exchanges, and make the data more accord with the actual marketing situation. In most cases, the data mining technology and online processing (OLAP) analysis method for company use, can also be used alone, to select the correct mining algorithm is very important. Such as analysis of telecom customer in which state in the life cycle, need to use regression analysis; Analysis to retain the loss of users, according to the past, damn user characteristics predict whether the user has to use classification algorithm.

Data visualization is the use of graphics, image processing, and user interface, the user clear effectively communicate data message. At present, the general data visualization technology mainly in the form of tables, graphs, maps, etc. realizes graph linkage, graph transformation, form drilling, multi-dimensional switching, map data is highlighted, and other functions. Big data processing according to the classification which can be divided into big data query and data analysis, database technology, flow and complex event processing, distributed file system, etc. The data sharing mechanism is shown in the figure 1.

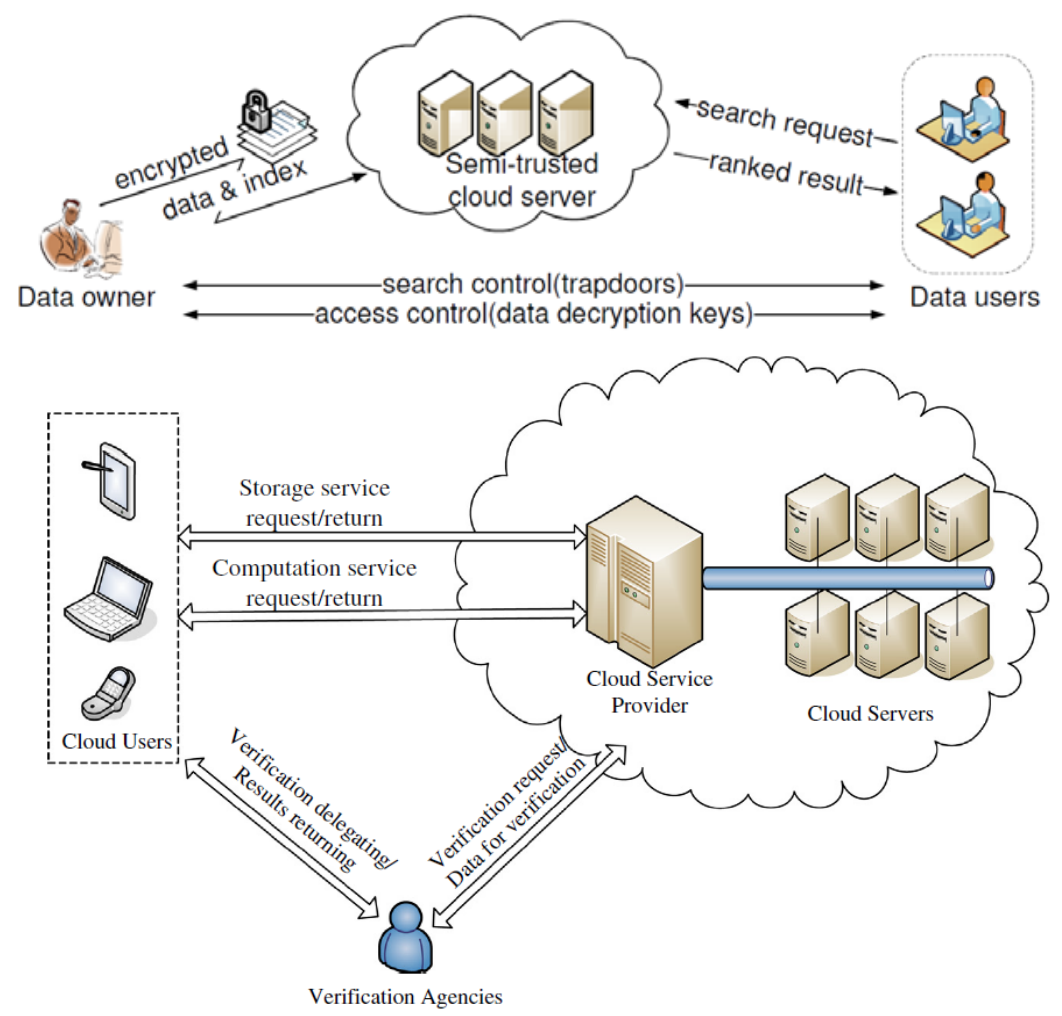

Fig. 1The Data Sharing Mechanism

Data mining is typically based on a certain data sources, these data sources may be all kinds of database, based on the mining database types are divided into relational data mining, spatial data mining, etc. According to the classification of mining technology are fuzzy and rough set method, artificial neural network, genetic algorithm, the decision tree, nearest neighbor technique, rule 
induction, visualization technology, etc. For the web, when users browse and visit will leave a mark or access information in the site, the access to information can be in the system of the server on the client to access information, access information on the server side, users with access to the system in which will produce a log record files, these log web services to access information mining is the main data objects.

\section{System Design and Theoretical Analysis}

Business management, with the emerging and all-round development of big data, related practice and research are increasingly presents the change trend of some significance. First of all, under the background of big data, the production and value creation is increasingly towards socialization and public participation. As the change of social information generation and dissemination way, the relationship between enterprises and consumers tend to equality, interaction and mutual influence. Second, the operation of the enterprise and its ecological are increasingly towards networking and dynamic. Modern enterprise production management and business decisions to a large extent depends on the social media and Internet population, the cooperation of upstream and downstream of the enterprise and the competition of "ecological system", and gradually showing a vertical integration and horizontal integration of two kinds of new trends. In the aspect of vertical integration, large-scale enterprise groups closely linked to supply chain as a link, symbiotic collaboration, mutual benefit, so as to realize the value chain of supply chain, and then to the transition of the network chain; In terms of transverse joint, networked business model changed the competition between enterprise organization model, make long-distance geographical distribution, multiple enterprises of organizational equality and independence. Third, enterprise understanding and insight into demand for market is increasingly toward the real time and accurate. The rapid accumulation of huge amounts of data to make enterprises difficult to timely insight into the useful information to make marketing decisions, but also brings unprecedented opportunities for the enterprise marketing. Users created by big data online and social networks in the information dissemination mechanism research should be focus on emerging applications such as social networks created by ordinary users of information content (UGC) and the transmission mechanism, which may contain the market opportunities and business success or failure. In the modern society, based on the interaction of the Internet, communication between the user and contact become very common and frequent, become the most important characteristics of a new generation of electronic commerce. This kind of interaction, communication and contact the data and information on the consumer purchase decision, enterprise business performance, as well as the relations between the enterprise and the customer had a profound impact. Under the condition of network, enterprise can record or collect customer in each channel. The system is shown in the following figure 2 .

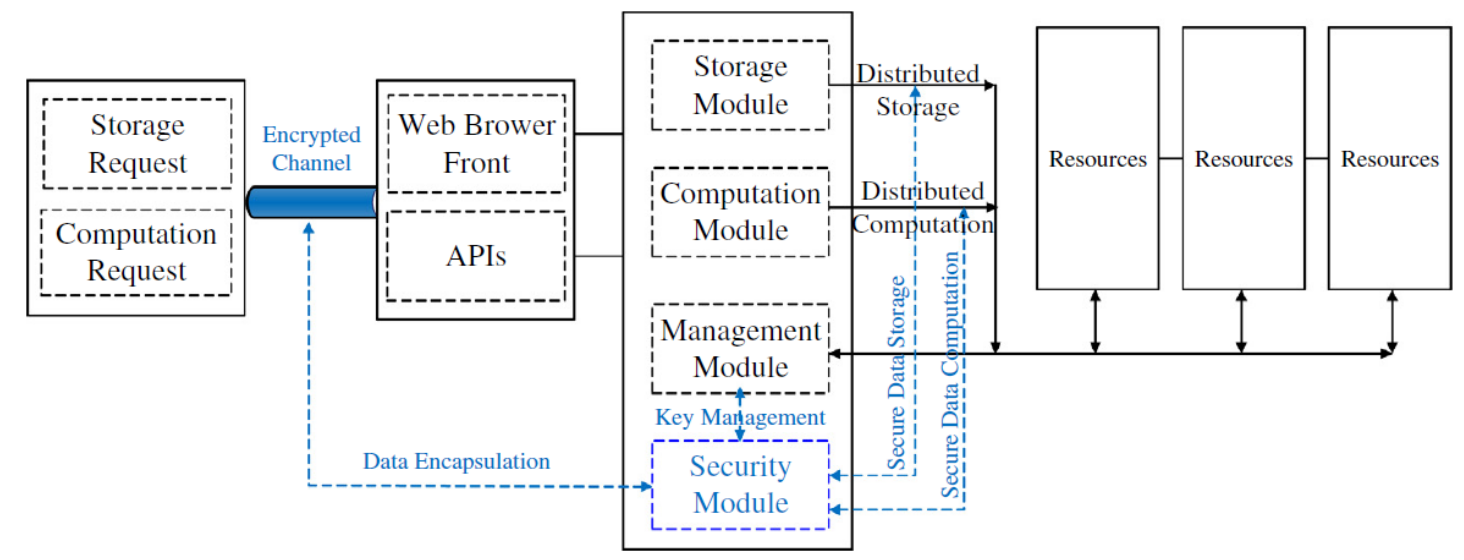

Fig. 2 The Structure of the System

Based on big data platform of emerging business model research should focus on big data driven emerging industrial chain. As e-commerce platform of two-sided market, and the third party network platform with all the parties of supply and demand of interactive data, thus to master the unique 
comprehensive market information. This kind of information to reduce the information asymmetry between the two sides of supply and demand in the market, solve market failure, improve enterprise profit and consumer surplus has a key role, as well as a variety of business model innovation based on these large data platform provides a huge market opportunity. The source of the business model innovation depends on how well unearthed from the vast amounts of bilateral market data useful to both sides of supply and demand, the traditional market research could not provide information, and the evolution of the bilateral understanding and management of the entire market.

\section{Experiment and Result}

In order to validate the proposed cloud-based mobile Internet big data engine design, user behavior analysis in the laboratory with PC server set up four nodes Hadoop distributed platform, one of the master node, three from the node for the test scenarios by big data warehousing, compared with single machine running environment, test the size of the 850 groups of different data system under the circumstance of operation time. The result is evident that our system is more effective.

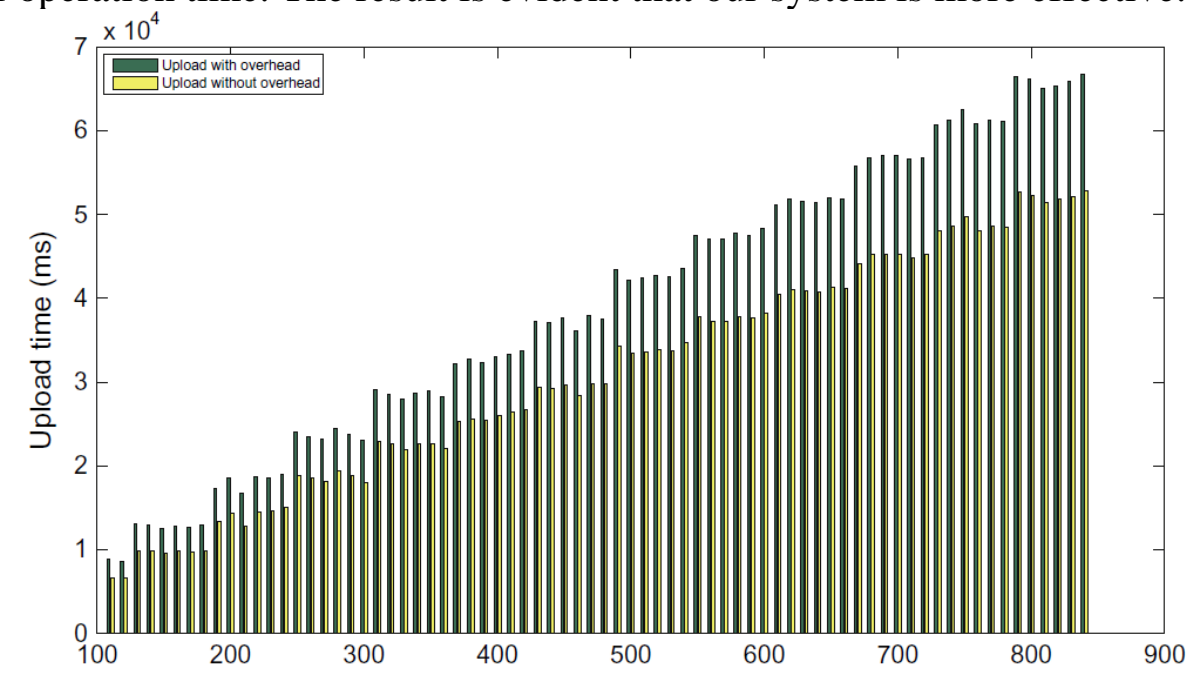

Fig. 3 The Result of the Experiment

It is different from the data analysis, database design, and system logic according to the implementation of data mining, data table need to be designed specifically for data mining. Data mining is the one-dimensional Boolean association rules, the transaction database design should give priority to with each calling user key, the user visited industry ID for the project, mining the frequent pattern set for the industry, get association rules set by frequent phase, the correlation industry, used for joining enterprises. For data mining, in addition to the use of advanced mining algorithm, and studies a new mining algorithm, improve the efficiency of data mining, to solve the problem of the huge amounts of data, or update the encountered in the excavation, etc., should also be treated effectively throughout all along the line. The data preprocessing, from the beginning of the data mining, began to prepare specification data. In the real world, may be due to the equipment failure data collection, person or a computer error, the occurrence of errors in the data transmission and so on, to repeat, or naming conventions or inconsistent data used in the code, input fields, such as the date format is not consistent, makes the database are easily affected by noise data and data and inconsistent data gaps.

Adopt reasonable enterprise data analysis and data mining technology to access features analysis and the mining association industry, is the basis of accurate marketing system must implement the function module, because the system is the application of business in the data analysis and based on the mining results. A customer care system geared to the needs of the user's application business is based on data analysis, through the analysis enterprise call records, get the time characteristic of the enterprise users was concerned, geographical features, etc., makes the enterprise to have accurate grasp of user access rules, and based on user access is used to adjust the enterprise marketing measures accordingly; Two other application system of business link push and industry promotion, is 
based on data mining to achieve results, and the user to SMS, voice reservations, system will be pushed to the enterprise users mining results, by the enterprises to choose the marketing information to associated industries, enlarge the coverage of the marketing information, for more accurate potential customers, potential customers into the possibility of enterprise users.

\section{Conclusion and Summary}

Since humans created the Internet, it has quietly changed and changing people's social and economic behavior, at the same time, it has given rise to many emerging technologies continue to expand and promote the human creation and application scope of information and data. What mechanism design, product and business model is the key to decide whether or not a business model is successful and the research direction includes data application platform for the new business model and profit sources of research, the study of the patterns of cloud computing and charges, revenue model research on the application of the large data. Big data era has arrived, and will become the world's next the forefront of innovation, competition and productivity. When people are convinced that "by the human will be able to on the big data exchange, integration and analysis to discover new knowledge and create new value, a big, big, big profit and the development of science and technology knowledge", management, information and scholars in the field of mathematics and other related responsible efforts to explore how to found in the large data knowledge and theory, technology and method to create and make contribution to the progress and development of human society. In the near future, we decide to combine more related techniques to polish the current method.

\section{References}

[1] Xianggen S, Ningyu H, Zhuxuan L, et al. Feasibility analysis and investigation of precision marketing on blood donor recruitment in the countryside[J]. Chinese Journal of Blood Transfusion.

[2] Ebadollahi S, Hu J, Kohn M S, et al. Method and system for outcome based referral using healthcare data of patient and physician populations: US, US8660857 B2[P]. 2010.

[3] Dichev, D., Koev, H., \& Louda, P. (2014). A measuring system with an additional channel for eliminating the dynamic error. Journal of Theoretical \& Applied Mechanics, 44, 1, 3-20.

[4] Wood(Group)Co., W. G. H., \& Economics and Polytechnic College; L. ;. (2014). The analysis on the application of precision marketing in b2c e-commerce. Journal of Beijing Institute of Economics \& Management.

[5] Linzhi D, Xiaoman S, Xiao C. Design of Intelligent Marketing System Based on E-Commerce Trading[C]. //Sixth International Conference on Measuring Technology and Mechatronics Automation. IEEE Computer Society, 2014:243-246. 